\title{
Biomechanical Analysis of Balance and Gait Posture by Obesity Level in Adolescents
}

\author{
Chong-hoon Lee ${ }^{1}$ and Youn-Girl Jeon ${ }^{2}$ \\ ${ }^{1}$ Department of Sports Science, Seoul National University of Science \& Technology, \\ Seoul, Korea \\ 1leejh36@snut.ac.kr
}

\begin{abstract}
The purpose of this study is verifying the effectiveness of balance as a tool to correct a youth's wrong gait posture through comparative analysis of balance and gait among the youth group of normal-weight, overweight and obesity, and studying of the comparison of balance and gait with degree of obesity (Body Mass Index: BMI) and biomechanical gait analysis. There was a statistically significant difference in stability test items ( $p<.05)$. In a step width obese adolescent statistically significant difference $(p<0.001)$ was found. As the step width is one of gait factors, obese and overweight adolescent has large step width compare to normal adolescents. These results suggest the view, obese adolescents compared to normal weight adolescents lack balance, and step width is wider. When balance is better, step width and obesity level are reduced. When step width is shorter, the obesity level is lower. As a result, if the balance is better, the gaits close to how normal weight adolescents walk, because, in conclusion, if balance improves the gait will be corrected.
\end{abstract}

Keywords: We would like to encourage you to list your keywords in this section

\section{Introduction}

Obesity in adolescent population is continuously growing although it is a preventable and has been the cause of various illnesses. Socio-economic cost of obesity keeps on increasing and the loss of self-esteem, depression, and negative psychological and social problems have been associated with it. It became beyond the individual's problems but emerged as a problem in society.

Although walking can be utilized to address obesity problem, it can be a burden on the body in obese adolescents (Hochberg et al., 1995). Inappropriate gait pattern and posture associated with obesity may increase loadings on joints and lead to injury and osteoarthritis (Hochberg et al., 1995). Since balance control is an essential component for the optimal functioning of any locomotors system (Winstein, 1989), gait and balance control together needs to be investigated in order to correct inappropriate performance and prevent injury. This study aims to evaluate the relationship between gait posture and balance control in obese adolescents.

\section{Methods}

\subsection{Subjects}

In this study, the subjects were 10th grade male students in high school and free of any orthopedic disease. Twenty two subjects were divided into 3 groups based on their BMI (Body Mass Index: BMI); normal weight (8), overweight (6), and obese group (8) <Table 1>. 
Table 1.Subject Parameters Based on BMI

\begin{tabular}{llll}
\hline \hline Groups & $\begin{array}{l}\text { height }(\mathrm{cm}) \\
\mathrm{M} \pm \mathrm{SD}\end{array}$ & $\begin{array}{l}\text { mass(kg) } \\
\mathrm{M} \pm \mathrm{SD}\end{array}$ & BMI \\
\hline Normal $(\mathrm{n}=8)$ & $171.86 \pm 4.94$ & $61.81 \pm 6.42$ & $\sim 23.24$ \\
\hline Overweight $(\mathrm{n}=6)$ & $177.67 \pm 5.49$ & $77.65 \pm 5.43$ & $23.25 \sim 24.74$ \\
\hline obese $(\mathrm{n}=8)$ & $173.09 \pm 3.64$ & $89.43 \pm 9.71$ & $24.75 \sim$ \\
\hline
\end{tabular}

\subsection{Experimental Procedures}

Subjects fasted 12 hours before the experiment. BMI was calculated using height and weight obtained from TANITA TBF-202 instrument. Dynamic balance control was evaluated with SI(stability index) measurement which reflects the distance that center of pressure traveled during the task using Balance SD system (Biodex) <Figure 1>. The lower score indicates better performing postural control. When subjects lost control, they were allowed to grab the handle. If they were not able to reposition themselves in a short period, the trial was considered invalid and performed again.

3D coordinate data were obtained using infrared light 12 cameras (Eagle-4, Motion)<Figure 2>. 53 reflective markers were placed on subjects for static calibration and 16 segments were created. 8 markers were taken off and remaining 45 markers involving lower extremities and spine were used for coordinate data $\langle$ Figure 3$\rangle$.

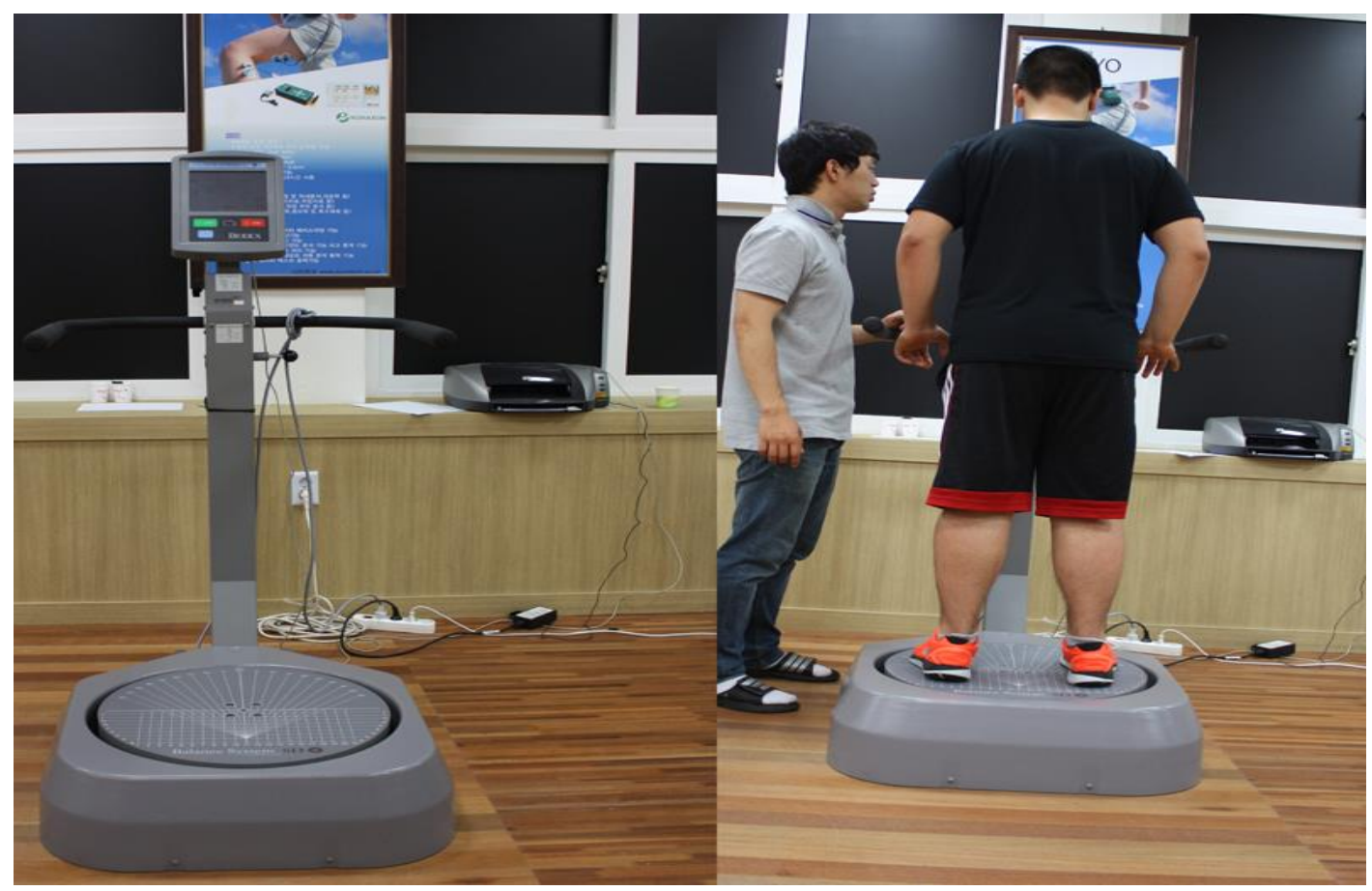

Figure 1. Balance Control Measurement 


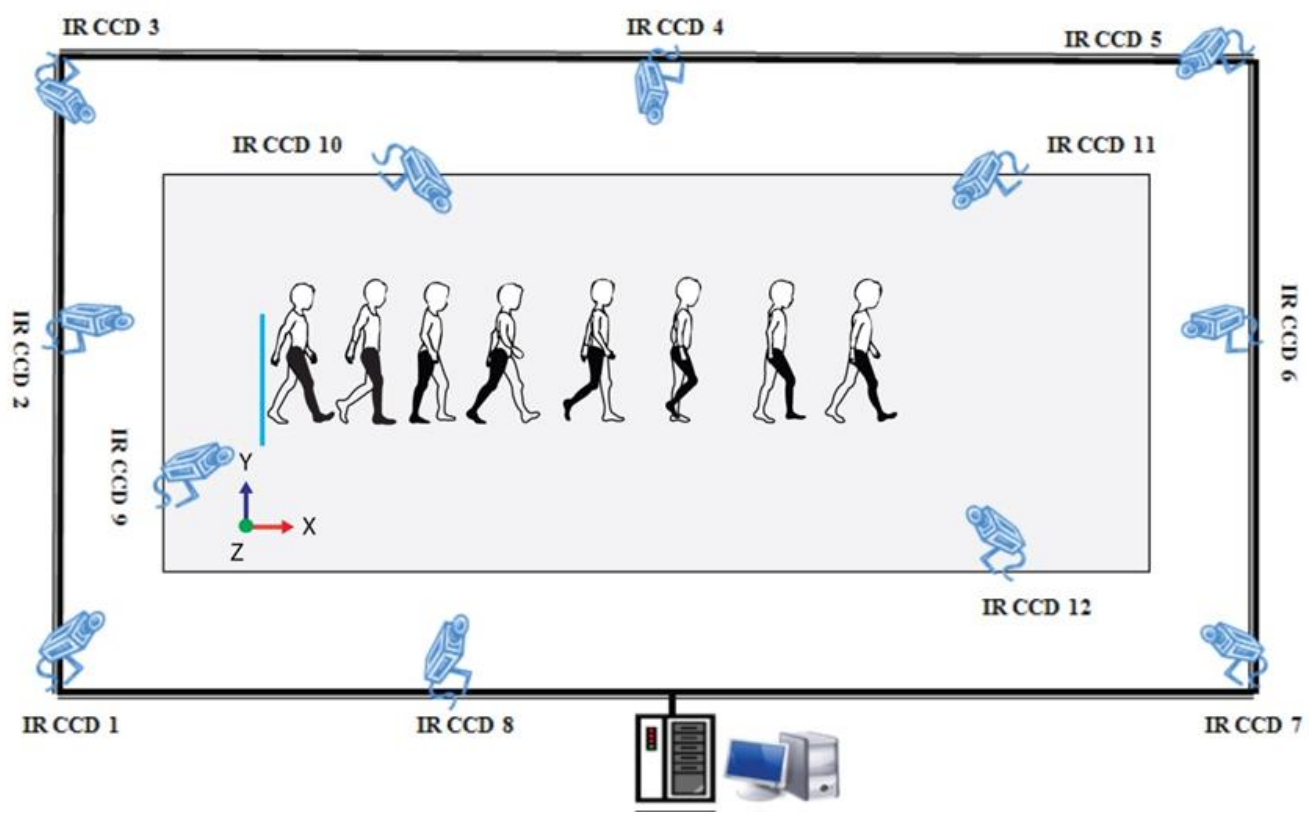

Figure 2. Experimental Set-up

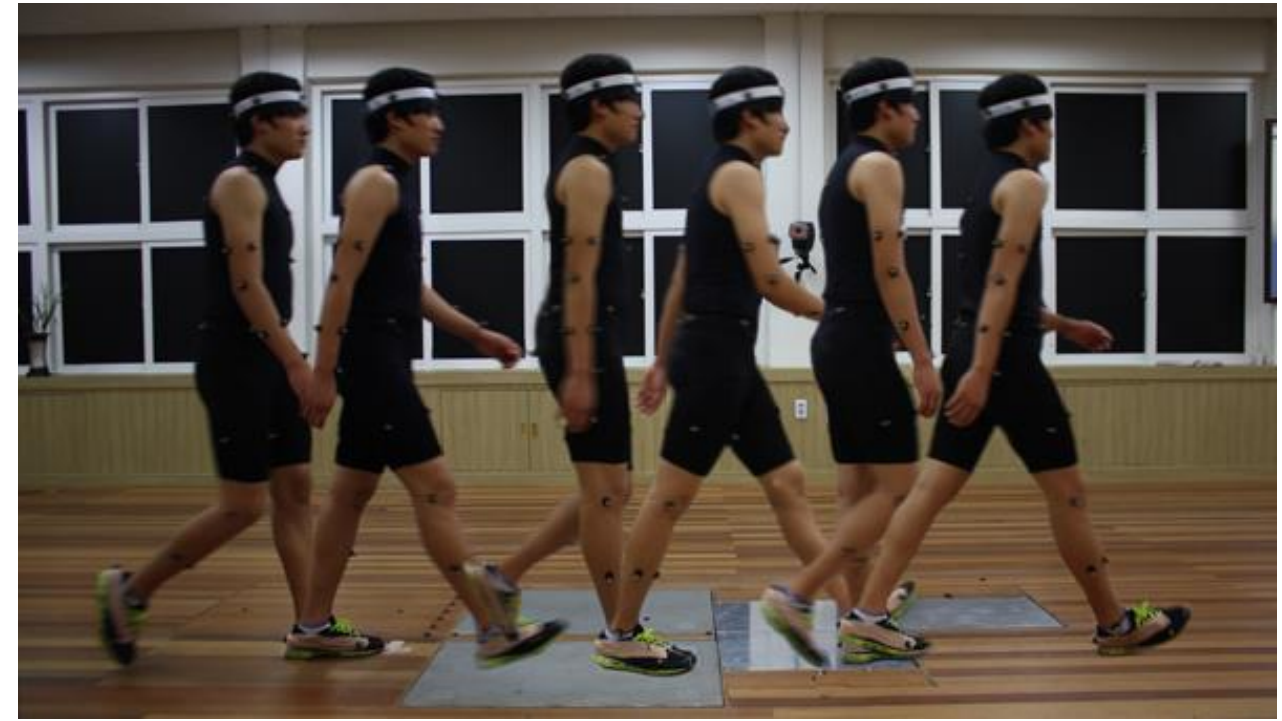

Figure 3.Gait Posture Assessment

\subsection{Data Analysis}

3D coordinate data were obtained using Cortsx 3.0 (Motion Analysis) then kinematic and kinetic data were analyzed with Visual 3D program. MANOVA was performed using average (M) and standard deviation (SD) data from 3 out of 5 total gait trials (SPSS19.0). Alpha level was set at .05. 


\subsection{Gait Event}

Gait events were defined as Figure 4 and the time variables in the events were analyzed.

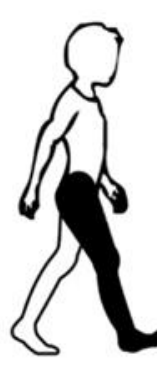

$\mathrm{RHC1}$

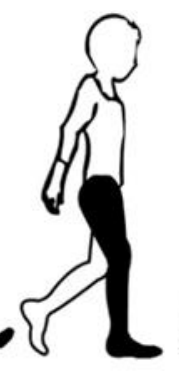

LTO

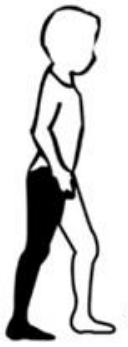

Figure 4. Gait

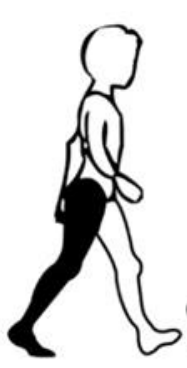

$\mathrm{LHC}$

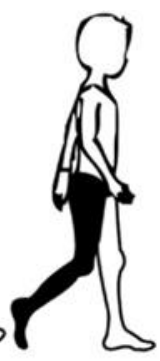

RTO
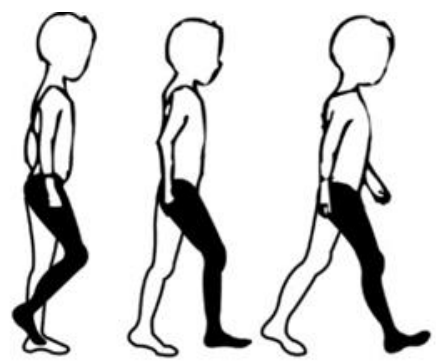

RHC2

Figure 4. Gait Cycle by Event

\section{Results}

\subsection{MANOVA between Obesity and Balance Control}

Table 2. BMI Level $\times$ Balance Control MANOVA

\begin{tabular}{lllllll}
\hline \hline & $\begin{array}{l}\text { Normal } \\
\mathrm{M} \pm \mathrm{SD}\end{array}$ & $\begin{array}{l}\text { Overweight } \\
\mathrm{M} \pm \mathrm{SD}\end{array}$ & $\begin{array}{l}\text { Obesity } \\
\mathrm{M} \pm \mathrm{SD}\end{array}$ & $\mathrm{F}$ & $\mathrm{P}$ & $\begin{array}{l}\text { Post Hoc } \\
\text { (Tukey })\end{array}$ \\
$\begin{array}{l}\text { Posture } \\
\text { Stability }\end{array}$ & $-1.28 \pm 0.23$ & $-1.42 \pm 0.41$ & $-1.94 \pm 0.21$ & 12.259 & $.000 * * *$ & $\begin{array}{l}\mathrm{c}<\mathrm{a}, \\
\mathrm{c}<\mathrm{b}\end{array}$ \\
$\begin{array}{l}\text { Single Leg- } \\
\text { Right }\end{array}$ & $-1.93 \pm 0.52$ & $-2.28 \pm 0.63$ & $-3.31 \pm 0.88$ & 8.393 & $.002 * *$ & $\begin{array}{l}\mathrm{c}<\mathrm{a}, \\
\mathrm{c}<\mathrm{b}\end{array}$ \\
$\begin{array}{l}\text { Single Leg- } \\
\text { Left }\end{array}$ & $-2.03 \pm 0.37$ & $-2.92 \pm 0.98$ & $-3.03 \pm 0.88$ & 3.933 & $.037 *$ & $\mathrm{c}<\mathrm{a}$ \\
\hline
\end{tabular}

$*=(p<.05), * *=(p<.01), * * *=(p<.001), a:$ normal, b: overweight, $\mathrm{c}:$ obese

Postural stability (bilateral) was significantly different in groups $((\mathrm{F}=12.259, \mathrm{p}<.001)$. Post hoc test revealed significant difference between normal and obese groups (I-J:0.66, $\mathrm{p}=.001$ ) and overweight and obesity groups(I-J:0.52, p=.007), respectively. No significant difference was observed between normal and overweight groups.

Results from single leg-right condition was significantly different in groups ( $\mathrm{F}=8.393$, $\mathrm{p}<.01)$. Post hoc test revealed that normal and obese groups (I-J:1.39, $\mathrm{p}=.002)$ and overweight and obese groups (I-J:1.03, $\mathrm{p}=.034)$ differ significantly. There was no significant difference between normal and overweight groups.

Results from single leg-right condition demonstrated significant difference in groups $(\mathrm{F}=3.933, \mathrm{p}<.05)$. Normal and obese groups significantly differed (I-J:1.00, $\mathrm{p}=.045)$. No difference was found in the other comparisons.

\subsection{MANOVA between Obesity and Gait Parameters}

Step width significantly differed in groups $(\mathrm{F}=13.927, \mathrm{p}<.001)$. The difference was observed between normal and obese groups (I-J:6.09, $\mathrm{p}<.001)$ and between normal and overweight groups (I-J:3.73, $\mathrm{p}=.020)$. No other difference was observed. 
Table 3.BMI Level × Gait Parameter MANOVA

\begin{tabular}{|c|c|c|c|c|c|c|}
\hline & $\begin{array}{l}\text { Normal } \\
\mathrm{M} \pm \mathrm{SD}\end{array}$ & $\begin{array}{l}\text { Overweight } \\
\mathrm{M} \pm \mathrm{SD}\end{array}$ & $\begin{array}{l}\text { Obesity } \\
\mathrm{M} \pm \mathrm{SD}\end{array}$ & $\mathrm{F}$ & $\mathrm{P}$ & $\begin{array}{l}\text { Post Hoc } \\
\text { (Tukey) }\end{array}$ \\
\hline Step Length & $75.66 \pm 3.19$ & $75.86 \pm 4.48$ & $77.03 \pm 4.16$ & 0.274 & .764 & - \\
\hline Step Width & $18.99 \pm 2.50$ & $22.72 \pm 2.54$ & $25.10 \pm 1.94$ & 13.927 & $.000 * * *$ & $\begin{array}{l}a<c, \\
a<b\end{array}$ \\
\hline $\begin{array}{lr}\text { Toe } & \text { O } \\
\text { RHC1 } & \text { Rfoc } \\
01 & \\
\end{array}$ & ot $10.98 \pm 2.11$ & $13.64 \pm 4.26$ & $12.54 \pm 3.01$ & 1.294 & .297 & - \\
\hline $\begin{array}{l}\text { Toe Out LTO } \\
\text { Rfoot } 02\end{array}$ & $9.75 \pm 4.43$ & $10.75 \pm 4.20$ & $10.22 \pm 2.24$ & 0.125 & .883 & - \\
\hline $\begin{array}{l}\text { Toe Out LHC } \\
\text { Rfoot } 03\end{array}$ & $10.52 \pm 4.37$ & $12.80 \pm 4.43$ & $12.97 \pm 3.46$ & 0.870 & .435 & - \\
\hline $\begin{array}{ll}\text { Toe } & \text { Ot } \\
\text { LHC1 } & \\
\text { Lfoot 01 } & \end{array}$ & $9.49 \pm 5.74$ & $12.22 \pm 2.69$ & $11.00 \pm 5.25$ & 0.537 & .593 & - \\
\hline $\begin{array}{l}\text { Toe Out RTO } \\
\text { Lfoot } 02\end{array}$ & $7.53 \pm 6.46$ & $8.31 \pm 3.34$ & $8.06 \pm 4.67$ & 0.043 & .958 & - \\
\hline $\begin{array}{l}\text { Toe Out RHC } \\
\text { Lfoot } 03 \\
\end{array}$ & $8.07 \pm 5.98$ & $9.99 \pm 3.42$ & $8.92 \pm 4.84$ & 0.254 & .778 & - \\
\hline RSP & $0.61 \pm 0.05$ & $0.65 \pm 0.53$ & $0.64 \pm 0.33$ & 2.027 & .159 & - \\
\hline LSW & $0.411 \pm 0.024$ & $0.42 \pm 0.019$ & $0.42 \pm 0.022$ & 0.208 & .814 & - \\
\hline LSP & $0.51 \pm 0.03$ & $0.54 \pm 0.04$ & $0.53 \pm 0.03$ & 0.822 & .454 & - \\
\hline RSW & $0.42 \pm 0.01$ & $0.42 \pm 0.02$ & $0.41 \pm 0.02$ & 0.170 & .845 & - \\
\hline
\end{tabular}

\section{Conclusion}

The study observed that the normal weight groups performed better in all of the balance tests than the overweight groups. It supports the outcome of the study that overweight subjects have less balance control compared to normal weight subjects (Jung-Seok Ok, 2012, Seung-Sub Cho, 2010). There were differences in the classification of groups compared to current study. Jung-Seok Ok used BMI $25 \mathrm{~kg} / \mathrm{m}^{2}$ or more as overweight but current study classified it as obese according to WHO classification (WHO, the classification of adult obesity-BMI standards, 2000). If these studies used the same standard, the results are not different.

The reason that obese adolescents have less balance control is maybe because they have lost balance function as they move less and continue living in sedentary style. Another possible explanation is that unwanted weights may have hindered movements necessary for balance control biomechanically (Blaszczyk, 2009). The reason this study used negative numbers for balance index is that the lower number represents better balance control (Balance Sd System Operation Manual, Biodex).

Altered step width can be explained by the view that step width and double support time reflect balance capabilities and step length and stride time are associated with gait reflex patterns (Gabell, 1984). Therefore, disrupted balance will result in increased step width.

If we assume narrower step width is more close to normal gait pattern, we conclude that having better balance control lead to better gait posture. This means that gait pattern is highly correlated with balance control capabilities (Judge, et al., 1995) and the obese adolescents who have minimum daily activities may have lost balance capabilities. In other words, increasing balance control with training may correct gait pattern. 


\section{References}

[1] K Berg, "Balance and its Measure in the Elderly: A review, Physiother Cn", vol. 41, (1989), pp. 240-26.

[2] J. W. Blaszczyk, , J. Gieslkinska-Swider, M Plewa, B. Zahorska-Markiewicz, \& A. Markiewicz, "Effects of Excessive Body Weight on Postural Control”, Journal of Biomechanics, vol. 42, no. 9, (2009), pp. 1295-1300.

[3] A. Gabell, U. S. L. Nayak, "The Effect of Age and Variability in Gait", J. Gerontol, vol. 39, (1984), pp. 662666.

[4] M. C. Hochberg, M. Lethbridge-Cejku, W. W. Scott Jr, R. Reichle, C. C. Plato \& J. D. Tobin, (1995).

[5] J. O. Judge, M.B. King, R. Whipple, "Dynamic Balance in Older Persons: Effects of Reduced Visual and Proprioceptive Input, J. Gerontol, vol. 50, (1995), pp. 264-270.

[6] C. J. Winstein, E. R. Grander, \& D. R. McNeal, "Standing Balance Training: Effect on Balance: Locomotion in Hemiparetic Adults", Arch plays Med Rehabil, vol. 70 no. 10, pp. 755-762.

[7] C. D. Scott and R. E. Smalley, J. Nanosci. Nanotechnol, vol.3, (1989), p. 75.

[8] Biodex Medical System Inc. Balance System SD Operation/Service Manual, FN: 080-060 2/08., pp.163-275.
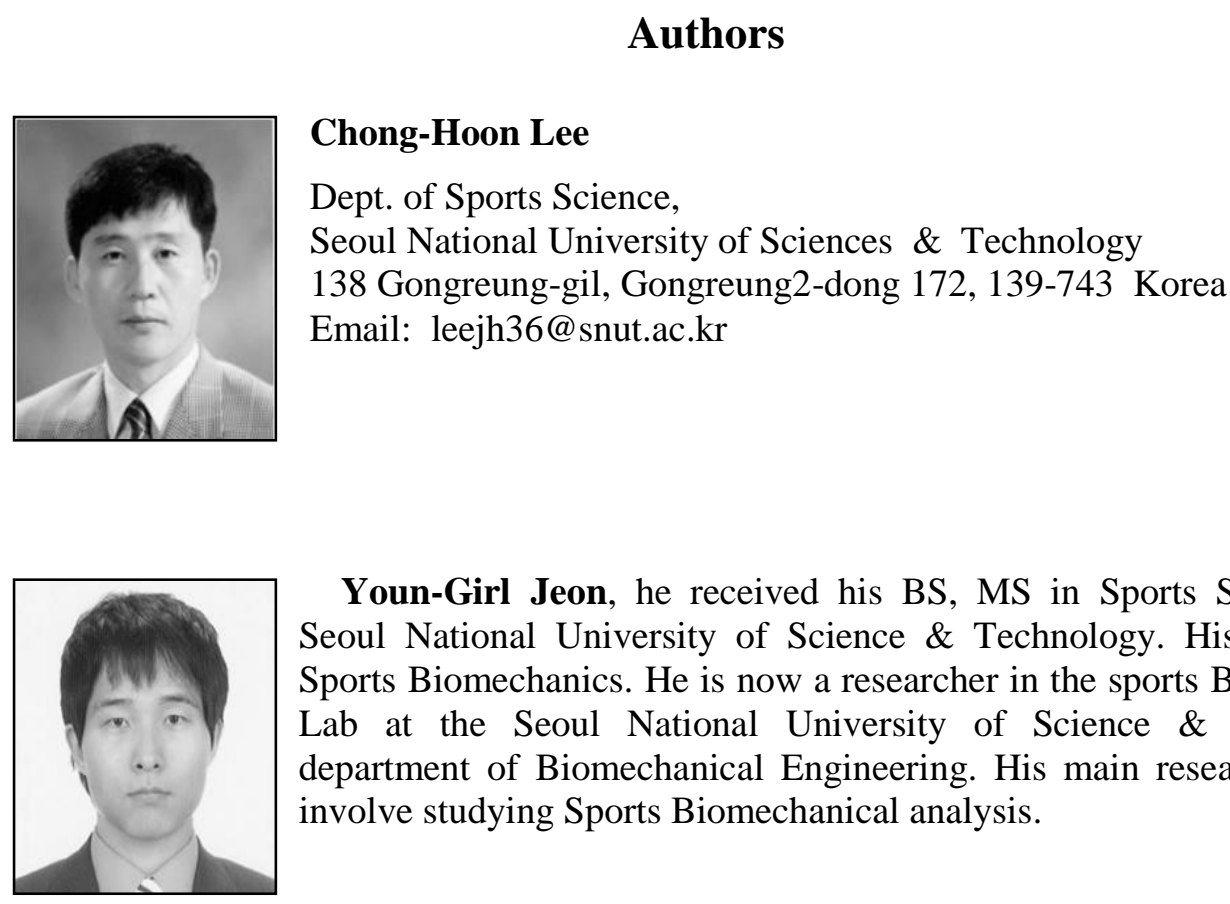

Youn-Girl Jeon, he received his BS, MS in Sports Science from Seoul National University of Science \& Technology. His major is a Sports Biomechanics. He is now a researcher in the sports Biomechanics Lab at the Seoul National University of Science \& Technology, department of Biomechanical Engineering. His main research interests involve studying Sports Biomechanical analysis. 